\title{
The Use of Ageratum Conyzoides L. [Asteraceae] As A Therapeutic Measure In The Treatment Of Breast Myiasis Sores In Rural Women And Associated Bacteria.
}

\author{
Ogbalu, O. K. And Williams, J.O.
}

\begin{abstract}
This study reports for the first time on the use of ethanolic extract of Ageratum conyzoides in women with breast myiasis. A total of fifty rural women were examined [ages 18-62 years old] and 17.25\% had breast myiasis at the fishing settlements at Okoikri and Oyorokotor of Rivers State Nigeria. Women with cutaneous breast myiasis were treated with ethanolic leaf extracts of Ageratum conyzoides. Different numbers of maggots were extracted from the breasts and 92.7\% of nursing mothers had their sores healed after the application of ethanolicic extract of A. Conyzoides. After the extraction of larvae of Cordylobia anthropophaga, the application of ethanolic extract of A. Conyzoides extract caused the dryness of the open sores. The microbiological quality of the leaves, stem, flower and consortium of the leaves, stem and flower of Ageratum conyzoides was assessed showing the presence of some species of bacteria. Microbial quality of the plant parts was done to assess the presence of bacteria in the leaves, stems and flowers parts. The consortium of leaves, stem and flower had the highest bacterial count followed by the leaves, stem and flower. Total bacterial counts of the leaves, stem, flower and consortium were $2.5 \times 10^{7} \mathrm{cfu} / \mathrm{g}, 1.6 \times 10^{7} \mathrm{cfu} / \mathrm{g}, 6.6 \times 10^{4} \mathrm{cfu} / \mathrm{g}$ and $1.3 \times 10^{8} \mathrm{cfu} / \mathrm{g}$ respectively. Bacterial isolates identified included Bacillus subtilis, Staphylococcus aureus, Pseudomonas aeruginosa and Escherichia coli. The implication of Staphylococcus aureus, Bacillus subtilis and Eschericia coli to public health are of great significance.
\end{abstract}

Keywords: Ageratum conyzoides, therapy, breast myiasis sore, rural women, bacteria.

\section{Introduction}

Medicinal plants constitute an effective source of both traditional and modern medicines. Herbal medicine has been revealed to have valid utility and in Nigeria, about $80 \%$ rural population depends on its efficacy for their primary health care. Scientist from diverse fields in a similar efforts are investigating new flora with an eye to their therapeutic worth. A sense of urgency accompanies the search as the pace of species extinction continues.

Anthropogenic activities as well as urbanization are major factors that are affecting the growth, multiplication of Ageratum conyzoides, it is an annual herb with a long history of traditional medicinal uses in many countries of the world, especially in the tropical and subtropical regions. A wide range of chemical compounds including alkaloids, flavonoids, chromenes, benzofurans and terpenoids have been isolated from this species. Extracts and metabolites from this plant have been found to possess pharmacological and insecticidal activities [Okunade, 2002].

A. conyzoides has been widely studied. It is believed that a detailed information as presented in this review on its phytochemistry and various biological properties of the extracts and the constituents might provide incentive for proper evaluation of the use of the plant in medicine and in agriculture. Some small companies in Brazil are reported to be using A. conyzoides as raw material for phytochemicals. The author has used the leaves to treat fresh wounds with great success. Test conducted in mice and rats for anti-inflammatory, analgesic and antipyretic activities have shown significant results without adverse side effects. Similarly clinical trials with arthrosis patients conducted with the ethanolic extract of the whole plant did not show any side effect [Marques-Neto et al., 1988]. The major constituents of the essential oil have been shown to produce precocious metamorphosis in insect larvae as well as sterility, moribound and dwarfishness in adult insects. Further work, however, still needs to be carried out on the toxicity of the plant and especially on the precocenes, which have been shown in few cases to cause hepatotoxicity in rats [Halpin et al., 1984; Hammond et al., 1995] .

\section{Materials And Methods}

Prior to the commencement of the study we sought and obtained an ethic permit from the Ethics Committee of the Department of Medical Laboratory Sciences of the Rivers State University of Science and Technology, Port Harcourt. A copy of the ethic permit was given to each village head and consent of the patients was sought. The categories of women examined for the study included nursing mothers [NM]; Childbearing women [CBW]; these two categories of women were between 18 and 38 years old, also the teenage [TNG] the other category of women covered those that were already into menopause [MW]. This group served 
as the control and received only topical application of distilled water. The other two categories of women received topical application of 40ppm ethanolic extract of A. conyzoides. The number of sores associated with breast myiasis was counted and recorded per breast. Breasts of women infected by the myiasis agents were periodically [at 4 hourly interval] wiped with clean hand towels dipped in 40ppm ethanolic extracts of A. Conyzoides four times daily. Women that had myiasis infection with open sores were divided into three groups and the number of women in each group depended on the number with myiasis infection. The trial was replicated five times.

\section{Plant Material}

Conyzoides were collected in the month of March 2014 from the Department of Applied and Environmental Biology of the Rivers State University of Science and Technology, Port Harcourt, Nigeria.

\section{Preparation Of The Extract.}

The leaves, stems and flowers of Ageratum conyzoides were collected from the Department of Applied and Environmental Biology of the Rivers State University of Science and Technology, Port Harcourt. The plant parts were washed under a running tap to remove the adhering dirt and sand. All the plant parts $[4 \mathrm{~g}]$ were blended using in Moulinex Blender and extracted in 70\% ethanol and 40ppm was made from the stock after the method of Orlu and Ogbalu, 2013.

\section{Microbiological Quality Analysis Of Ageratum Conyzoides}

The leaves, stem and flower of the Ageratum were obtained from the Botanical garden of the Applied and Environmental Biology Department of the Rivers State University of Science and Technology, Port Harcourt, Nigeria. These parts were washed with distilled water, air dried for a few days and ground. They were sent to the Laboratory for culture analysis. The agar used were nutrient agar (Laboratory M. Bury, Lancashire ,U.K.),macconkey agar and Potato dextrose agar(PDA, Harrigan and mccance,1990).

Bacterial and Fungal Viable Counts

The method used was the 10-fold dilution method of Harrigan and mccance(1990).Ten grams $(10 \mathrm{~g})$ each of the ground leaves, stems, flowers and consortium of leaves, stems and flowers were aseptically transferred into $90 \mathrm{ml}$ of sterile normal saline in $150 \mathrm{ml}$ conical flasks. The flasks were shaken vigorously to dislodge the microbial flora. Further 10 -fold dilutions were carried out by adding $1.0 \mathrm{ml}$ of the penultimate dilution to $9 \mathrm{ml}$ of fresh diluents. Finally, $0.1 \mathrm{ml}$ of an appropriate dilution was placed on dried nutrient agar, evenly spread with a sterile glass spreader and incubated at $30^{\circ} \mathrm{c}$ for $24 \mathrm{hrs}$. At the end of the incubation period, counts were performed for the dilutions with counts between 30 to 300 colonies (Anonymous, 1994). All counts were performed in duplicates and the average taken.

Mould and yeast counts were enumerated by aliquots of appropriate diluted samples on acidified potato dextrose agar containing streptomycin $(1 \mathrm{mg} / 100 \mathrm{ml})$. The plates were incubated at $30^{\circ} \mathrm{c}$ and counted after 48 hours for yeasts and 96 hours for moulds.

Similarly, $0.1 \mathrm{ml}$ of appropriate dilutions was inoculated on macconkey agar. Mean colony counts were calculated and expressed as colony forming units per gram (cfu/g) of the sample analyzed ( Harrigan and mccance, 1990).

Representative colonies of the ten-fold dilution of the leaves, stems, flowers and consortium of the leaves, stems and flowers were picked and sub cultured on nutrient agar until pure cultures were obtained. The pure cultures were stored on agar slants.

\section{Identification And Characterization Of Isolates}

The methods described in Cheesebrough (2000) were adopted in characterization of isolates. Isolates were identified by standard methods (Abbey, 2007).

Statistical tool

Results were subjected to statistical analysis employing the student t-test at $95 \%$ and $99 \%$ probability levels.

\section{Results And Discussion}

The total heterotrophic bacteria microscopic characteristics isolated from the leaves, stems, fruits and consortium of the Ageratum is shown on table 1.The total bacterial population of the leaves, stem, flower and consortium of leaves, stem and flower were $2.5 \times 10^{7}, 1.6 \times 10^{7}, 6.6 \times 10^{4}$ and $1.3 \times 10^{8} \mathrm{cfu} / \mathrm{g}$ respectively. Moulds and Yeasts were not obtained from the samples.

The identification of Bacillus subtilis, Staphylococcus aureus, Pseudomonas aeruginosa and Escherichia coli was done with reference to Harrigan and mccance (1990) and Cheesebrough (2000) 
Statistical Analysis:

We adopted purposive sampling and we used analysis of variance.

\section{Results}

Out of a total of fifty rural women examined [ages 18-62 years old], $17.25 \%$ had breast myiasis at the fishing settlements at Okoikri and Oyorokotor of Rivers State Nigeria.

Data collected showed in Fig.1 wounds of C. Anthropophaga larvae in a 38 year-old nursing mother. Fig. 2 showed the number of maggots of Cordylobia anthropophaga extracted from breasts of different categories of women in a Fishing settlement at Emenafor, Rivers State. The number of maggots collected from breasts of nursing mothers was significantly higher [13.5 larvae, $n=30]$ than those from the breasts of other categories of women [8.6 larvae in CBW] and [ 3.4 in MN ] [Fig.2], after an interval of three weeks, the sores in the breasts started healing [Fig.3]. In Fig. 4, the assessment on the efficacy of A. Conyzoides for the treatment of breast myiasis sores showed more than $92.7 \%$ cure in nursing mothers that received the treatment and they significantly differed from the category of women in their child bearing age that had 85.9[approximately 86\%] cure [DMRT; P < 0.05].

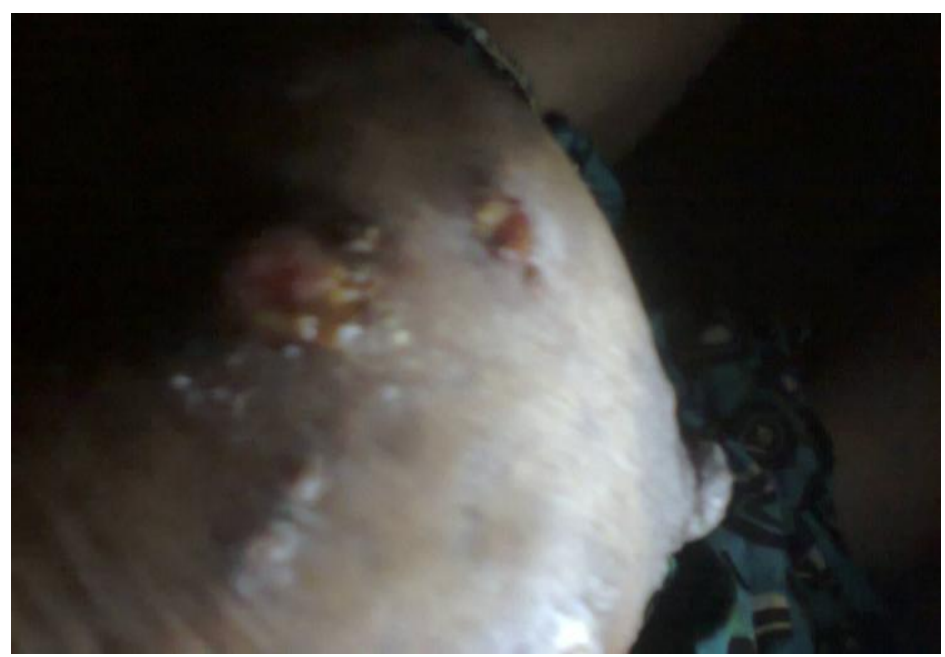

Fig.1. Wounds Of C. Anthropophaga Larvae Prior To The Application Of Ethanolicic Extract Of A. Conyzoides.

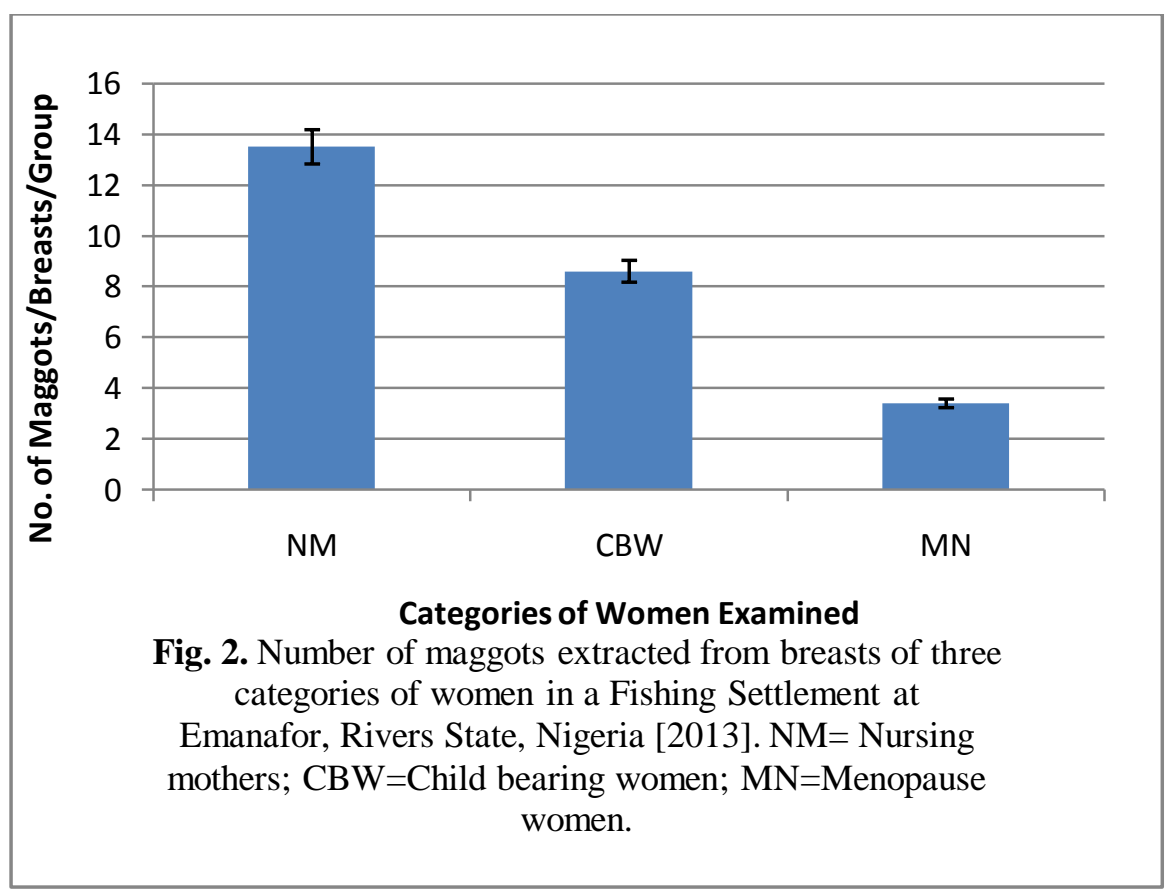




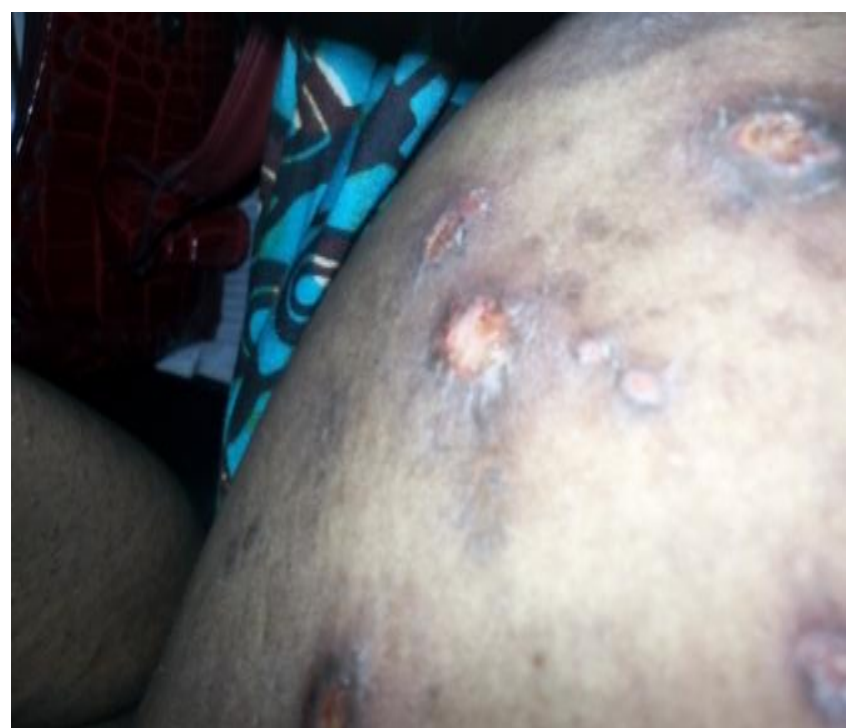

Fig. 3. The Infected Left Breast Of A 38 Year-Old Fish Farmer [A Nursing Mother] With Sores Of C. Anthropophaga; Breast Undergoing Treatment With Ageratum Conyzoides.

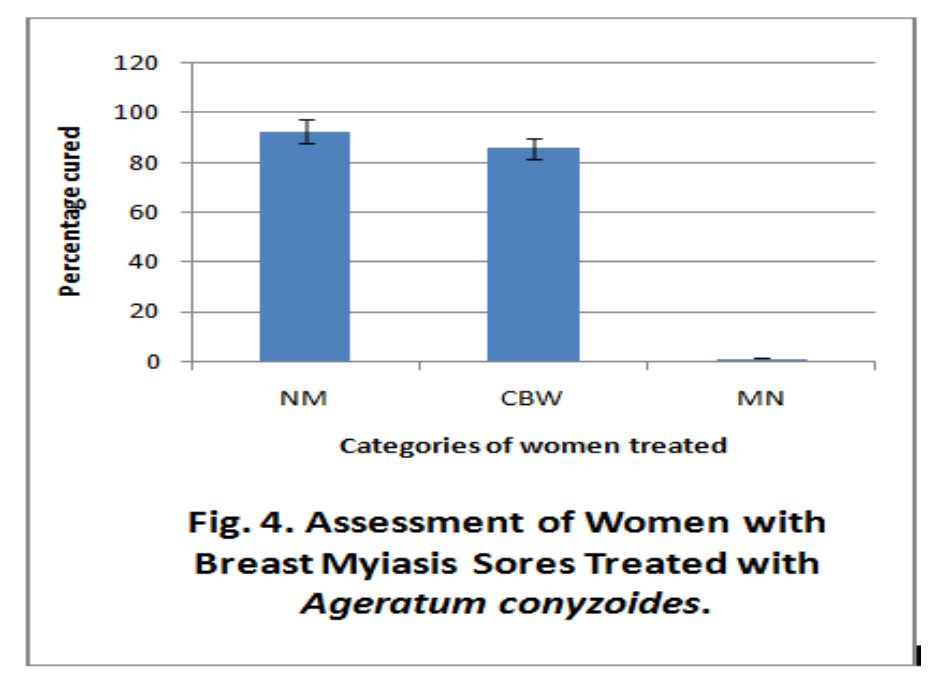

\section{Discussion}

Over the years, WHO advocated that countries should interact with traditional medicine with a view to identifying and exploiting aspects that provide safe and effective remedies for ailments of both microbial and non- microbial origins (WHO 1978). Twenty-eight rural women of the Niger Delta were infected with the human warble fly (Tumbu fly) larvae, Cordylobia anthropophaga, and of the women examined, 22 (78.5\%) were nursing-mothers [Ogbalu et al., 2006].

The therapeutic and protective roles of Ageratum conyzoides had been reported [Okunade, 2002; Kokwaro, 1976; Ita et al., 2007; Ita et al., 2009]. In the eastern states of Nigeria, A. Conyzoides is taken as a spice in porridges and records showed that spices have also been recognized to possess medicinal properties and their use in traditional systems of medicine has been on record for a long time. With the advancement in the technology of spices and on knowledge of the chemistry and pharmacology of their active principles, their health benefit effects had been reported [Srinivasan, 2005]. These studies documented digestive stimulant action, hypolipidemic effect, antidiabetic influence, antilithogenic property, antioxidant potential, antiinflammatory property, antimutagenic, and anticarcinogenic potential of spices. Among these, the hypocholesterolemic and antioxidant properties of a few specific spices have far-reaching nutraceutical value. These beneficial physiological effects also have the potential of possible therapeutic application in a variety of disease conditions [Srinivastan, 2005]

In Nigeria and some African countries, the plant has been used in the treatment of scabies, craw-craw, ringworm, ulcers and some other skin diseases without any adverse effects. In the eastern states of Nigeria the leaves had been used in wound dressing and a decoction is used in relieving pains associated with omphalitis and colic. Generally, it is used traditional medicine for its antiasmathic activities and for the curing of various 


\begin{tabular}{lllllllllllllllll}
\hline+ & - & + & - & + & - & + & + & - & - & + & + & + & + & + & Staphylococcus aureus \\
+ & - & + & - & + & - & + & + & - & - & + & + & + & + & + & Staphylococcus aureus \\
+ & - & + & - & + & - & + & + & - & - & + & + & + & + & + & Staphylococcus aureus \\
\hline
\end{tabular}

Cat- catalase; Oxi-oxidase; Coag-coagulase; In- indole; MR-methyl red; VP- Voges Proskaeur;

$\mathrm{NO}_{3-}$ nitrate reduction; $\mathrm{H}_{2} \mathrm{~S}$ - hydrogen sulphide; Cit- citrate; +- positive; -, negative Glu- glucose; Suc-sucrose; Mal- maltose; Mann- mannitol.

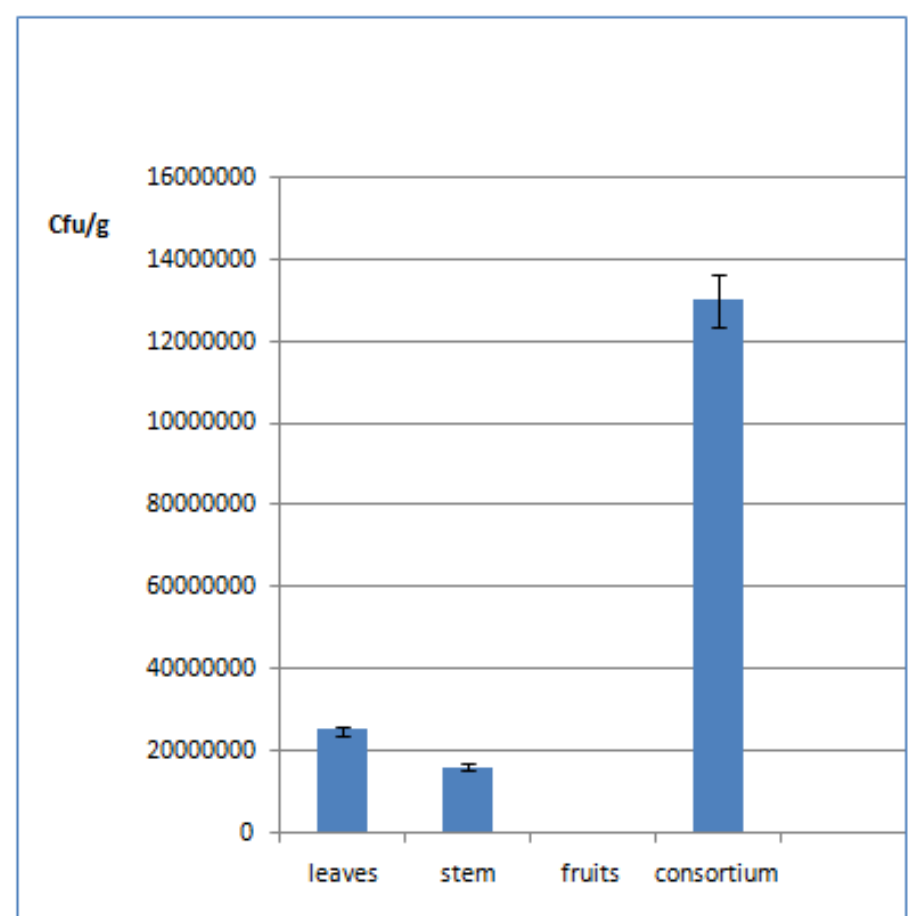

Fig.1: Total Bacterial Count In Different Parts Of Ageratum

Herbal plants such as Ageratum conyzoides contain some phytochemical components like saponins, tannin, alkaloids etc. These phytochemical components are known to have antimicrobial effects. ( Oyetayo and Oyetayo,2006). For these phytochemical components to be extremely effective in antagonizing the pathogenic activities of invading micro organisms, a large quantity of the plants must be applied. The presence of microorganisms of public health significance like Bacillus subtilis, Escherichia coli and Staphylococcus aureus may be as a result of improper handling of the plants by passer-by and contaminated equipment ( Frazier and Westhoff,2003). Pseudomonas aeruginosa is a ubiquitous microorganism found in environments like soil, water, humans, animals, plants etc Also the unhygienic lifestyles and habits of passers-by such as spitting of saliva, coughs and even defecation will introduce microorganisms on A. Conyzoides that grows in the garden, roadside and parks from where the plants were harvested.

A comparative study was done to observe the bacterial load present in the leaves, stem, fruits and consortium. From figure 1, it was shown that the Consortium had the highest bacterial load. In the descending order, it is as follows: Consortium $>$ leaves $>$ stem $>$ fruits.From the students' $T$-test table, there was significant difference at 0.05 and 0.01 probability levels between the consortium and the fruits also,between the stem, leaves and the fruits.

\section{Conclusion}

This study has demonstrated that ethanolic plant parts of Ageratum conyzoides possess some cytotoxic and therapeutic properties and it has added to the knowledge and evidence for its potential benefits in patients with breast myiasis sores. Although our sample size was small; it targeted only a cross section of the community. It provided pain relief in patients that applied it to wound sites and we recommend that it can be used to clean wounds of myiasis after extraction of myiasis-causing larvae in the rural villages where there might be no access to hospitals or health care centres. We recommend that further investigations be done to validate our findings in order to assess other potential benefits of the plant. 


\section{References}

[1]. Abbey, S.D.(2007) Foundation in medical Mycology ( $4^{\text {th }}$ edn.).Kenalf Publication, Port Harcourt, Nigeria.22-30.

[2]. Anonymous (1994).Annual Book of ASTM Standards. Water and Environmental Technology,11:2(Water 11).520523,ASTM,Philadelphia,PA.

[3]. Cheesebrough,M.(2000). District Laboratory Practice in Tropical Countries ,Part 2.Cambridge Univ.Press;UK,35-38,62-69.

[4]. Frazier,W.C. and Westhoff,D.C. (2003). Food Microbiology,4th edition . Mcgraw-Hill Publishing Company Ltd. 66-67.

[5]. Harrigan W.F. and mccance M.E.(1990). Laboratory Method in Food and Dairy Microbiology, Academic Press,London.

[6]. Ita, S.O., Akpanyung, E.O., Umoh, B.I., Ben E.E. and Ukafia, S.O. (2009) Acetaminophen Induced Hepatic Toxicity: Protective Role of Ageratum conyzoides. Pakistan Journal of Nutrition, 8:928-932.

[7]. Jagetia, G.C., Shirwaikar, A., Rao, S.K. and Bhilegaonkar, P.M. (2003) Evaluation of the radioprotective effect of Ageratum conyzoides Linn extract in mice exposed to different doses of gamma radiation. Journal of Pharmacy and Pharmacology, 55: 11511158 .

[8]. Juliana, H.C. N., Edlayne, G., Silvia, R., G., Roseane, F., Márcia O.M. M. And Joana D. F. (2010) Ageratum conyzoides essential oil as aflatoxin suppressor of Aspergillus flavus. International Journal of Food Microbiology, 137: 55-60.

[9]. Kahkonen, M.P., Hopia, A.I., Vuorela, H.J., Rauha, J.P., Pihlaja, K., Kulaja, T.S. et al. (1999) Antioxidant activity of plant extracts containing phenolic compounds. Journal of Agricul- ture and Food Chemistry, 47: 3954-3962.

[10]. Kamboj, A., and Saluja, A.K. (2008) Ageratum conyzoides L.:A review on Its phytochemical and pharmacological profile.International Journal of Green Pharmacy,2: 59-68.

[11]. Ogbalu, O. K. , Ted George Ody Achufusi. And E. E. Orlu [2012]. Epidemiology of Human Furuncular Myiasis of Cordylobia anthropophaga [Grunberg] in Nigeria. International Journal of Dermatology, Vol.52 Issue 3: 331-336.

[12]. Oyetayo, V.O. and Oyetayo,F.L. (2006). Phytochemical screening and antibacterial properties of Siam weed, Chromolaena odorata, leaf against aerobic isolates of wound. J. Applied Environ. Sc. 2(1):7-11

[13]. Treutter,D.[2006]. Significance of flavonoids in plant resistance:a review. Environ. Chem. Lett, 4 147-157

[14]. Srinivasan, D. [2005]. Roles of spices beyond food flavouring: Nutraceuticals with multiple health effects. Food Reviews International, Vol. 21, Issue 2: 167-188.

[15]. WHO [1978]. Report of the International Conference on Primary Health Care, Alma-Ata, 6-12 September, 1978. 